\title{
A Fur-like protein PerR regulates two oxidative stress response related operons $d p r$ and metQIN in Streptococcus suis
}

Tengfei Zhang, Yi Ding, Tingting Li, Yun Wan, Wei Li, Huanchun Chen and Rui Zhou*

\begin{abstract}
Background: Metal ions are important micronutrients in cellular metabolism, but excess ions that cause toxic reactive oxygen species are harmful to cells. In bacteria, Fur family proteins such as Fur, Zur and PerR manage the iron and zinc uptake and oxidative stress responses, respectively. The single Fur-like protein (annotated as PerR) in Streptococcus suis has been demonstrated to be involved in zinc and iron uptake in previous studies, but the reports on oxidative stress response and gene regulation are limited.

Results: In the present study, the perR gene deletion mutant $\Delta p e r R$ was constructed in Streptococcus suis serotype 2 strain SC-19, and the mutant strain $\triangle$ perR exhibited less sensitivity to $\mathrm{H}_{2} \mathrm{O}_{2}$ stress compared to the wild-type. The $d p r$ and metQIN were found to be upregulated in the $\Delta p e r R$ strain compared with SC-19. Electrophoretic mobility shift assays showed that the promoters of $d p r$ and metQIN could be bound by the PerR protein. These results suggest that $d p r$ and metQIN are members of the PerR regulon of $S$. suis. dpr encodes a Dps-like peroxide resistance protein, and the $d p r$ knockout strains ( $\Delta d p r$ and $\Delta d p r \Delta p e r R$ ) were highly sensitive to $\mathrm{H}_{2} \mathrm{O}_{2}$. MetQIN is a methionine transporter, and the increased utilization of methionine in the $\Delta p e r R$ strain indirectly affected the peroxide resistance. Using a promoter-EGFP gene fusion reporting system, we found that the PerR regulon was induced by $\mathrm{H}_{2} \mathrm{O}_{2}$, and the induction was modulated by metal ions. Finally, we found that the pathogenicity of the perR mutant was attenuated and easily cleared by mice.
\end{abstract}

Conclusions: These data strongly suggest that the Fur-like protein PerR directly regulates $d p r$ and metQIN and plays a crucial role in oxidative stress response in S. suis.

\section{Background}

Iron and zinc are recognized as important micronutrients for bacteria, but excess of iron can catalyze the Fenton reactions, resulting in formation of toxic hydroxyl radicals [1]. Similarly, an excess of zinc ions can also trigger the formation of hydroxyl radicals [2]. Besides hydroxyl radicals, reactive oxygen species (ROS) such as superoxide radical and $\mathrm{H}_{2} \mathrm{O}_{2}$ are inevitably generated as byproducts of aerobic metabolism in bacteria [3]. Additionally, during infection, ROS can be generated by the innate immune system[4]. ROS can cause damage to many macromolecules including DNA, proteins and lipids [5,6]. It is clear that oxidative stress and metal homeostasis are closely

\footnotetext{
* Correspondence: rzhou@mail.hzau.edu.cn

Division of Animal Infectious Diseases in the State Key Laboratory of Agricultural Microbiology, College of Veterinary Medicine, Huazhong Agricultural University, Shizishan Street, Wuhan, 430070, China
}

related. However, bacteria have evolved efficient mechanisms to maintain metal ion homeostasis and protect themselves from oxidative damage [7].

Fur family proteins are present widely in bacteria and play crucial roles in cellular processes. This family contains more than six different proteins. They are the sensors of iron (Fur and Irr) [8] [9], zinc (Zur) [10], manganese [11] and nickel (Nur) [12], and the peroxide regulon repressor (PerR) [13]. In the Gram-negative Escherichia coli, there are two Fur family proteins Fur and Zur. In contrast, there are three Fur-like proteins (Fur, Zur and PerR) in many Gram-positive bacteria such as Bacillus subtilis, Clostridium acetobutylicum and Staphylococcus aureus. In B. subtilis, Fur regulates iron uptake and siderophore biosynthesis; Zur regulates two $\mathrm{ABC}$ zinc transporters; and PerR regulates the oxidative stress response $[13,14]$. 
Streptococcus suis is economically a very important Gram-positive and facultative anaerobic bacterium that causes severe diseases in pigs and humans. As an emerging zoonotic pathogen, S. suis serotype 2 has become the predominant causative agent of adult human meningitis in Vietnam and Hong Kong [15]. Two large outbreaks of human infections were reported in China in 1998 and 2005, resulting in 229 infections and 52 deaths $[16,17]$. Like other bacterial pathogens, S. suis may also encounter both oxidative stress and metal starvation during infection. Thus, the regulation on the responses to oxidative stress and metal starvation by Fur-like proteins could be particularly important for S. suis survival in vivo and pathogenesis. However, only a single gene encoding a Fur-like protein has been found in each sequenced genome of $S$. suis, even in the genomes of most species of the genus Streptococcus. For example, the single Fur-like protein is encoded by SSU05_0310 in S. suis serotype 2 strain 05ZYH33 (GenBank accession no. CP000407). This protein has been defined as a zinc uptake regulator (Zur) [18], as well as an iron uptake regulator (Fur) in S. suis [19], but the research on its function in oxidative stress response is limited, whereas its homolog in Streptococcus pyogenes has been demonstrated to be a peroxide regulon repressor PerR [20-22]. In this study, the role of this Fur-like protein in peroxide resistance was confirmed in S. suis serotype 2. Therefore, we renamed this protein as PerR. At the same time, two target operons, $d p r$ ( $d p s$-like peroxide resistance protein) and metNIQ (methionine ABC-type transporter), were identified and proved to play important roles in oxidative stress response.

\section{Results}

Identification of a fur-like protein in S. Suis and other streptococci

In the genome of 05ZYH33 (a strain of S. suis serotype 2), the Fur-like protein encoded by SSU05_0310 had been first identified as a Zur [18], and we found that SSU05_0310 is the sole gene encoding a Fur-like protein in S. suis 05ZYH33. The SSU05_0310 protein consisted of 151 amino acids and contained a DNA-binding motif (Figure 1A). To identify the Fur-like proteins in other streptococci, a BLAST homology search using the sequence of SSU05_0310 was performed among the sequenced genomes of the members of genus Streptococcus. All streptococci had a single conserved Fur-like protein except that no Fur-like protein was found in Streptococcus pneumoniae. All the Fur-like proteins in streptococci and their homologs (Fur, Zur and PerR) in $B$. subtilis, S. aureus and C. acetobutylicum were used for cluster analysis, the result showed that the Fur-like proteins in streptococci clustered in the PerR group (Figure 1B). Furthermore, through sequence analysis, the key amino acid residues of PerR for $\mathrm{H}_{2} \mathrm{O}_{2}$ response and metal ions binding were highly conserved in SSU05_0310 protein (Figure 1A) [23]. Consequently, we named the single Fur-like protein in S. suis as PerR.

\section{Roles of PerR in $\mathrm{H}_{2} \mathrm{O}_{2}$ resistance in S. Suis}

Our sequence analysis suggested that PerR might be involved in the oxidative stress response in S. suis, and therefore we constructed a perR knockout strain ( $\Delta$ perR) and a functional complementing strain (CAperR). The growth of the wild-type, mutant and complementary strains showed no obvious difference in TSB medium with $5 \%$ newborn bovine serum (data not shown).

To characterize the roles of perR in the susceptibility of $S$. suis to peroxide stress, the sensitivity of the wildtype strain SC-19, mutant strain $\triangle p e r R$ and complementing strain $\mathrm{C} \Delta$ perR to $\mathrm{H}_{2} \mathrm{O}_{2}$ was compared using an inhibition zone assay. As shown in Figure 2A, the strains SC-19 and CAperR (about $16.3 \mathrm{~mm}$ and $16.1 \mathrm{~mm}$ in diameter) exhibited larger inhibition zones than the $\Delta$ perR strain (about $12.7 \mathrm{~mm}$ in diameter) when $4 \mu \mathrm{l}$ of $1 \mathrm{M} \mathrm{H}_{2} \mathrm{O}_{2}$ was used. To determine further the difference in $\mathrm{H}_{2} \mathrm{O}_{2}$ sensitivity, quantitative analysis was performed. As shown in Figure 2B, after $\mathrm{H}_{2} \mathrm{O}_{2}(10 \mathrm{mM})$ treatment, the perR mutant strain showed a higher survival rate than the wild type. The survival rate of the complementary strain $C \Delta$ perR was similar to that of the wild-type strain. These results indicated that inactivating $S$. suis perR led to reduced sensitivity to $\mathrm{H}_{2} \mathrm{O}_{2}$.

\section{Transcriptional regulation by PerR in S. Suis}

PerR has been recognized as an important regulator in bacteria. In order to identify members of the PerR regulon in $S$. suis, according to the consensus sequence of the PerR-box in $S$. pyogenes and B. subtilis (NTANAANNATTNTAN) [21,22], we screened for putative PerR-boxes in the -500 to +50 sequences of all the genes/operons in the S. suis 05ZYH33 genome. 12 predicted binding sites and 19 supposed target genes and operons were identified. The transcriptional levels of all 19 supposed target genes and operons (including $d p r$, metQ, relA and pmtA) containing prospective PerR-box in the promoters were compared between the strains SC-19 and $\triangle p e r R$ by real-time RT-PCR (Table 1$)$. Only three genes $d p r$ (Dps-like peroxide resistance protein), relA (GTP pyrophosphokinase) and metQ (methionine transporter) were significantly upregulated ( $\geq$ two-fold) in $\triangle$ perR (Figure 3A). Electrophoretic mobility shift assay (EMSA) showed that the His-tagged recombinant PerR protein could bind to the promoters of $d p r$ and metQIN, but not to those of relA, pmtA and gidA (gidA was used as the negative control, the results of relA and $p m t A$ were not shown) (Figure $3 \mathrm{~B}$ ). These results suggest that the $d p r$ gene and metQIN operon were directly regulated by PerR. The PerR boxes in the promoters of $d p r$ and 


\begin{tabular}{|c|c|c|c|}
\hline \multirow[t]{2}{*}{ A } & \multirow[b]{2}{*}{ DNA-binding motif } & \multirow[t]{2}{*}{ B } & \multirow{2}{*}{$100 \%$} \\
\hline & & & \\
\hline PerR (S. suis) & MEL ISHFNAENQTAFEHYIQHLKEKGIRITETRKAYVAYIIESh-DHPSAEMIYQDLIPN 59 & ST & \\
\hline $\operatorname{PerR}(B$. subtilis) & MARH---------ELKERLETLKETGURITPQRHAILEYL WNSM- AHPTADDIYKSLEGK 50 & SP & \\
\hline Zur (B. subtilis) & -----------MNVQEALNLLKENGYKYTNKREDILQLFADSD-R KLTAKNULSALNDD 47 & SD & \\
\hline \multirow[t]{2}{*}{ Fur (B. subtilis) } & ----------MENRIDRIKKQLHSSSYKL TPQREATVRVLLENEEDHLSAEDWYLL UKEK 50 & & \\
\hline & $\ldots: *: \ldots: * *$ & $\begin{array}{l}\text { SA } \\
\text { SM }\end{array}$ & \\
\hline PerR (S. suis) & YPHDSLATVMNLQLLLEEGFVTQLKRTHDNTTYYPF----MGHEHLVICEVDGKITDF 115 & & \\
\hline $\operatorname{PerR}($ B. subtilis $)$ & FPNMSVATWMNLRVFRESGL VKELTYG-DASSRFDF----VTSDHYHAICENCGKIVDF 105 & & \\
\hline Zur (B. subtilis) & YPGLSFDTIYRNLSLYEELGILETTELSGEKLFRF KS & BS-PerR & \\
\hline \multirow[t]{2}{*}{ Fur (B. subtilis) } & SPEIGLATVYRTLELLTELKWDKINFG-DGVSRYDLRKEGASHFHHLVCNECGAVDI 109 & SA-PerR & \\
\hline & $*: . . * *_{. .} *: * \quad .: \quad: \quad:$ & $\begin{array}{l}\text { CA-PerR } \\
\text { BS-Fur } \\
\text { SA-Fur }\end{array}$ & \\
\hline PerR (S. suis) & IDVEIPSLKKEAHTPTGYQITKEVLSIYGICPDCQN-------- 151 & CA-Fur & \\
\hline $\operatorname{PerR}($ B. subtilis) & HYPGLDEVEQLASHVTGFKVSHHRLEIYGVCQECSKKENH---- 145 & $\begin{array}{l}\text { CA-Zur } \\
\text { BS-Zur }\end{array}$ & \\
\hline Zur (B. subtilis) & ES---CPIDKLCDDLDGYQUSGHKFEIYGTCPDCTAENQENTTA 145 & SA-Zur & \\
\hline \multirow[t]{2}{*}{ Fur (B. subtilis) } & EGDLLEDVEEIIERDWKFKIKDHRL TFHGICHRCNGKETE---- 149 & & \\
\hline & $::: . .::: * * *$ & & \\
\hline \multicolumn{4}{|c|}{ 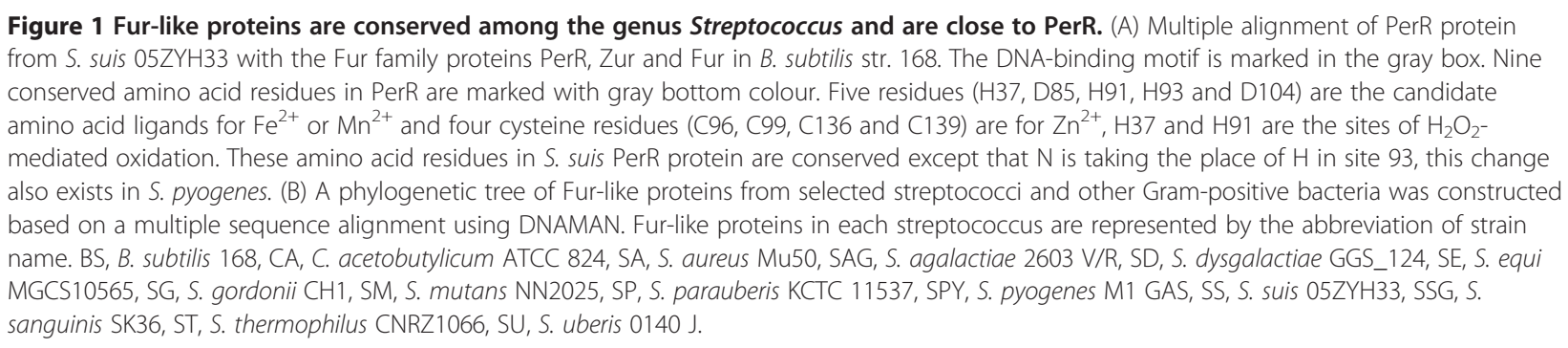 } \\
\hline
\end{tabular}

$m e t Q I N$ are shown in Figure 3C. To confirm regulation by PerR in S. suis, a transcriptional reporter plasmid pSET4s: $\mathrm{P}_{\mathrm{dpr}}$-EGFP was inserted into the genomes of strains SC-19 and $\triangle p e r R$. When cultured in TSB with $5 \%$ newborn bovine serum, stronger green fluorescence was observed in strain $\triangle$ perR:EGFP compared to SC-19:EGFP by fluorescence microscopy. The mean fluorescence intensity (MFI) was measured by flow cytometry (MFI of $\triangle p e r R$ :EGFP: $56.85 \pm 1.015$, MFI of SC-19:EGFP: $25.29 \pm 1.965$ ).

The effects of $\mathrm{H}_{2} \mathrm{O}_{2}$ on the transcriptional regulation were tested. Bacteria were stimulated by $10 \mu \mathrm{M} \mathrm{H}_{2} \mathrm{O}_{2}$ for $10 \mathrm{~min}$, the expression levels of $d p r$ and metQIN were analyzed by qRT-PCR. As shown in Figure 4A, $d p r$ and metQIN was obviously induced in SC-19 but not in $\Delta$ perR (cultured in TSB). Then, the EGFP reporter strains were used, the MFI of strains SC-19:EGFP and $\Delta p e r R$ :EGFP in chemical defined medium (CDM) was measured. As shown in Figure 4B, for the strain SC-19: EGFP, growth in medium with $50 \mu \mathrm{M}$ zinc and $50 \mu \mathrm{M}$ manganese led to a low green fluorescence level, and no obvious induction by $\mathrm{H}_{2} \mathrm{O}_{2}(10 \mu \mathrm{M})$ could be detected.
In contrast, when grown in medium with $50 \mu \mathrm{M}$ zinc and $50 \mu \mathrm{M}$ iron, SC-19:EGFP expressed a relatively high level of EGFP, and the MFI was about two-fold higher after induction by $\mathrm{H}_{2} \mathrm{O}_{2}$ for $1 \mathrm{~h}$. The MFI of strain $\Delta p e r R$ :EGFP was high and had no significant change in each condition. These results suggest that PerR regulated the target operons by binding to the promoter region, and the derepression was induced by $\mathrm{H}_{2} \mathrm{O}_{2}$ and influenced by metal ions.

Roles of $d p r$ in $\mathrm{H}_{2} \mathrm{O}_{2}$ resistance in S. Suis

$\mathrm{H}_{2} \mathrm{O}_{2}$ sensitivity analysis suggested that PerR was involved in oxidative stress response and we have found that $d p r$ was directly regulated by PerR in S. suis. $d p r$ encodes a peroxide resistance protein, previous study has found that $d p r$ mutant was highly sensitive to $\mathrm{H}_{2} \mathrm{O}_{2}$ [24]. To test the role of $d p r$ in $\mathrm{H}_{2} \mathrm{O}_{2}$ resistance, the $d p r$ gene was inactivated in strains SC-19 and $\Delta p e r R$. The resultant mutant strains $\Delta d p r$ and $\Delta p e r R \Delta d p r$ were subjected to the $\mathrm{H}_{2} \mathrm{O}_{2}$ sensitivity assay. Both $d p r$ mutant strains exhibited $<1 \%$ survival after incubation with 


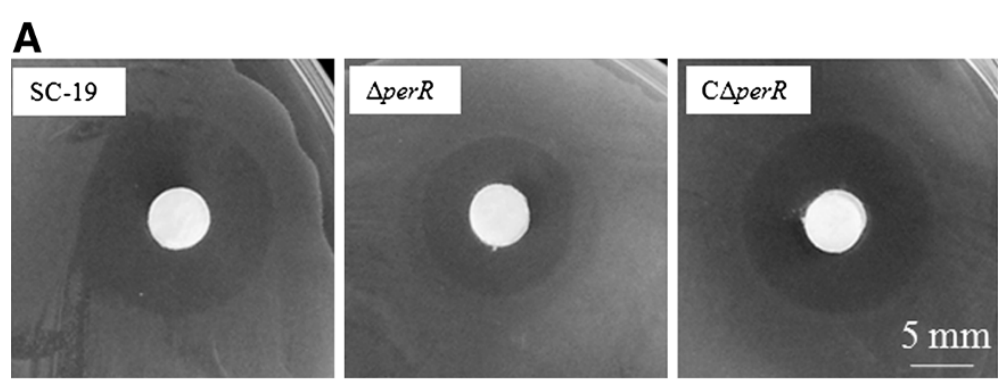

B

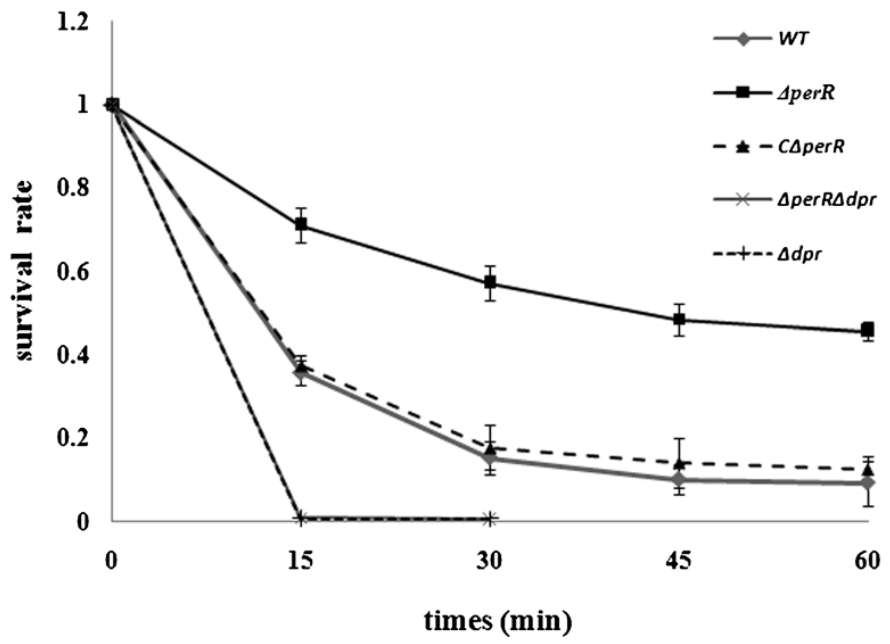

Figure 2 S. suis sensitivity to peroxide stress. (A) The $\mathrm{H}_{2} \mathrm{O}_{2}$ sensibility was tested by disk diffusion assay. $1 \mathrm{M} \mathrm{H}_{2} \mathrm{O}_{2}$ was used. (B) The survival rates of wild-type $(W T), \Delta$ perR, $C \Delta$ perR, $\Delta d p r$ and $\Delta p e r R \Delta d p r$ at every 15 min in TSB with $10 \mathrm{mM}$ of $\mathrm{H}_{2} \mathrm{O}_{2}$ challenge. Three independent experiments were performed.

$10 \mathrm{mM} \mathrm{H}_{2} \mathrm{O}_{2}$ (Figure 2B). Inactivation of $d p r$ led to near loss of $\mathrm{H}_{2} \mathrm{O}_{2}$ defensive capability in both $\Delta d p r$ and $\Delta p e r R \Delta d p r$ strains. However, there was no obvious difference in the survival rate between $\Delta d p r$ and $\Delta p e r R \Delta d p r$, suggesting that the increased $\mathrm{H}_{2} \mathrm{O}_{2}$ resistance of the perR mutant probably results of the derepression of $d p r$.

\section{Role of methionine in $\mathrm{H}_{2} \mathrm{O}_{2}$ resistance in S. Suis}

Expression of the methionine $\mathrm{ABC}$ transporter metQIN was upregulated in the $\Delta p e r R$, therefore, methionine uptake may have been increased in the mutant. To verify this hypothesis, the methionine utilization by strains SC19 and $\Delta p e r R$ was investigated by measuring the reduced amount of methionine in the CDM. There was no obvious different in the growth rate of strains SC-19 and $\Delta$ perR, but the amount of methionine utilization in the mutant was increased by $25.13 \%$ compared to the wild type in cells grown to late-log phase (Figure 5A). These data indicated that the derepression of metQIN led to increased accumulation of methionine in strain $\triangle p e r R$.

To investigate the role of methionine in oxidative stress, the $\mathrm{H}_{2} \mathrm{O}_{2}$ sensitivity of strains in CDM with different concentrations of methionine was tested. As shown in Figure 5B, strain SC-19 showed the lowest survival rate in $\mathrm{CDM}$ lacking methionine, and the survival rates were increased when methionine was added. The same phenomenon was observed in strain $\Delta$ perR, except that $\Delta$ perR showed higher survival rates at every methionine concentration. These results indicated that the resistance to $\mathrm{H}_{2} \mathrm{O}_{2}$ in $S$. suis was related to methionine.

\section{Role of PerR in pathogenicity in S. Suis}

An experimental infection model in mice was designed to assess the role of PerR in pathogenicity. In the wildtype group, all of the mice presented severe clinical signs associated with septicemia and septic shock during the first day post-infection and then died from septicemia in this group. In contrast, the mice in the $\Delta p e r R$ group presented with partial clinical signs, three of eight infected mice survived during $1 \mathrm{dpi}$, and finally one mouse was alive at $7 \mathrm{dpi}$. Thus, as previously report [25], the mutant strain $\Delta p e r R$ was slightly attenuated in pathogenicity according to survival rate and clinical signs.

To investigate the reason of the reduced pathogenicity in perR mutant, mice were intraperitoneally infected with 
Table 1 The results of PerR regulon's identification

\begin{tabular}{|c|c|c|c|c|c|}
\hline Predicted target genes ${ }^{\mathrm{a}}$ & Gene & s Function of genes & $\begin{array}{l}\text { Predicted PerR-box } \\
\text { NTANAANNATTNTAN }\end{array}$ & qRT-PCR & EMSA results \\
\hline SSU05_0022 & & aromatic amino acid aminotransferase & ATAAAACTATTATAA & $-2.5(0.6)$ & \\
\hline SSU05_0209 & & hypothetical protein & CTATAATCATITTAT & $+1.1(0.2)$ & \\
\hline SSU05_0308 & & hypothetical protein & GTAAAATTATTATAA & $-1.1(0.1)$ & \\
\hline SSU05_0309 & pmtA & cation transport ATPase & TTAGAATTATTATAATTA & $-1.1(0.1)$ & negative \\
\hline SSU05_0618 & & MATE efflux family protein & TTAAAATAATTATAA & $-4.2(1.1)$ & \\
\hline SSU05_1264 & & SAM-dependent methyltransferase & ATAGAATTATTATAA & $-1.1(0.3)$ & \\
\hline SSU05_1265 & & sulfatase & ATAGAATTATTATAA & $-1.8(0.3)$ & \\
\hline SSU05_1341 & lacl & Lacl family transcriptional regulator & TTAGAATCATTCTAG & $-1.8(0.4)$ & \\
\hline SSU05_1689 & $d p r$ & peroxide resistance protein & TTATAATTATTATAA & $+9.3(1.1)$ & positive \\
\hline SSU05_1691 & & phosphotyrosine protein phosphatase & TTATAATTATTATAA & $-1.7(0.4)$ & \\
\hline SSU05_1771 & metQ & lipoprotein transporter & ATACAATGATTGTAA & $+4.0(0.2)$ & positive \\
\hline SSU05_1855 & escA & ABC transporter ATP-binding protein & ATATAATTATTATAA & $-16.1(5.2)$ & \\
\hline SSU05_1856 & & HIT-family protein & ATATAATTATTATAA & $-1.6(0.4)$ & \\
\hline SSU05_2094 & relA & GTP pyrophosphokinase & GTATAATGATTGTAG & $+2.1(0.6)$ & negative \\
\hline SSU05_2095 & $c p d B$ & 2',3'-cyclic-nucleotide 2'-phosphodieste & e GTATAATGATTGTAG & $-3.0(1.1)$ & \\
\hline SSU05_2112 & & hypothetical protein & GTATAATGATTATAC & $-1.5(0.6)$ & \\
\hline SSU05_2113 & rarA & recombination factor protein & GTATAATGATTATAC & $+1.7(0.5)$ & \\
\hline SSU05_2191 & $r / m H$ & rRNA large subunit methyltransferase & ATAAAATAATTGTAA & $-1.3(0.3)$ & \\
\hline SSU05_2192 & htrA & trypsin-like serine protease & ATAAAATAATTGTAA & $+1.2(0.3)$ & \\
\hline
\end{tabular}

${ }^{\mathrm{a}} \mathrm{S}$. suis ORF number of $S$. suis $05 \mathrm{ZYH} 33$

${ }^{\mathrm{b}}$ Fold-change (standard deviation) of expression in $\Delta p e r R$ compared to expression in wild-type

the same dose of SC-19 and $\Delta p e r R$. Bacteria were recovered from blood, lung, brain and spleen. At $7 \mathrm{dpi}$, the numbers of $\Delta p e r R$ harvested from blood and each tissue were significantly decreased compared to those of the wild-type strain. At $11 \mathrm{dpi}$, the $\Delta p e r R$ was nearly cleared from mice, but the wild-type strain could still be recovered (Table 2). Statistical significance of the difference was determined by student $t$-test. The result suggested that the viability of perR mutant was reduced in the host.

\section{Discussion}

As a pathogen, S. suis may encounter both oxidative stress and metal starvation during infection. Fur family proteins play important roles in metal ion homeostasis and oxidative stress responses in many bacteria. A single Fur-like protein was identified in S. suis, and in the rest of the genus Streptococcus, except for S. pneumoniae. The Fur-like protein in S. suis has been shown to regulate the zinc and iron uptake genes $[18,19]$. In our study, the function of this Fur-like protein in oxidative stress response was characterized. We suggested that, in addition to its role in regulating zinc and iron uptakes, another important role of this Fur-like protein was to act as an oxidative stress response regulator in $S$. suis, and reannotated this Fur-like protein as PerR.

A recent research has found that the fur (perR) knockout mutant in S. suis serotype 2 strain P1/7 was more sensitive to $\mathrm{H}_{2} \mathrm{O}_{2}$ [25]. However, in our study, an opposite result was observed, that deletion of perR in S. suis serotype 2 strain SC-19 resulted in increased resistance to $\mathrm{H}_{2} \mathrm{O}_{2}$. Deletion of PerR has been found to cause a high resistance ability to $\mathrm{H}_{2} \mathrm{O}_{2}$ in $B$. subtilis [13], C. acetobutylicum [26] S. aureus [27], and in the single Fur containing S. pyogenes [21], and these results accord with our test in S. suis.

As a negative regulator, the high resistance to $\mathrm{H}_{2} \mathrm{O}_{2}$ in perR mutant may result from derepression of the PerR regulon. In many bacteria, one important member of PerR regulon for $\mathrm{H}_{2} \mathrm{O}_{2}$ resistance is catalase [28]. However, all lactic acid bacteria including $S$. suis lack catalase, it is interesting to identify other potential PerR targets for $\mathrm{H}_{2} \mathrm{O}_{2}$ resistance in $\mathrm{S}$. suis. qRT-PCR and EMSA tests showed that $d p r$ and metQIN were directly regulated by PerR, and the expression of $d p r$ and metQIN could be induced rapidly by physiological level of $\mathrm{H}_{2} \mathrm{O}_{2}$. These results suggested that one mechanism for oxidative stress response by PerR was derepression of PerR targets $d p r$ and metQIN. Previous study found that $f e o A B$ was regulated by Fur (reannotated as PerR in our study) in S. suis P1/7 strain [19], however, in our study the PerR protein could not bind with $f e o A B$ promoter as well as we did not found a PerR-box in the promoter region (data not shown), suggesting that it is an indirectly regulation. 
A

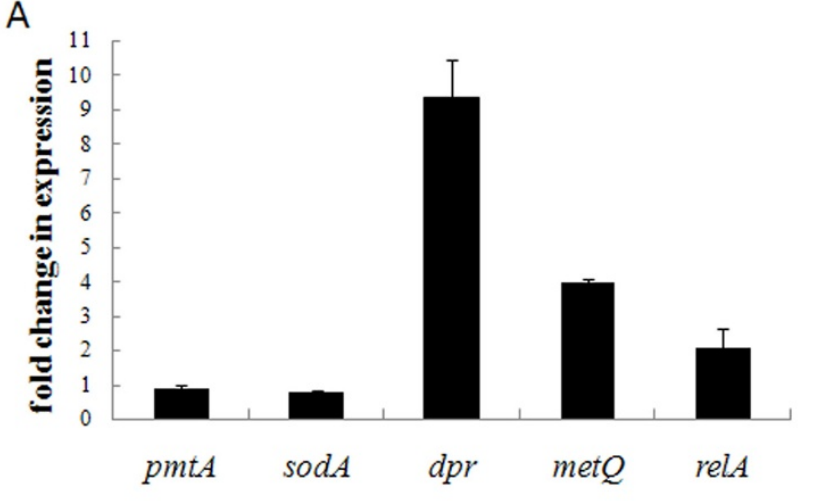

C
B

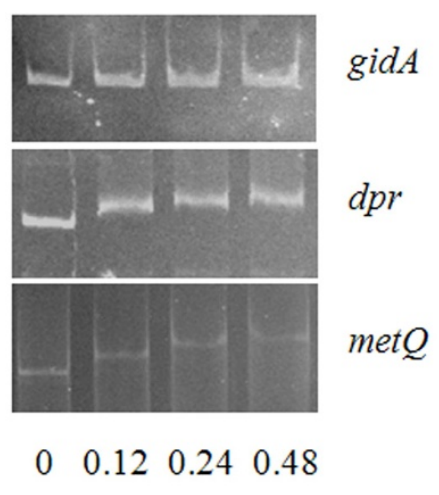

$\operatorname{PerR}(\mathrm{nM}) \quad 0 \quad 0.12 \quad 0.24 \quad 0.48$

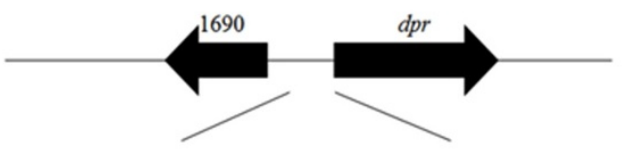

AATAATTCAGAGGAGGAGGGATAATT ITGCAATTTTTCTTC
Per-box TTTTATTTATAAT ATTATAAATAAAAGAAAGGGT ATATATG

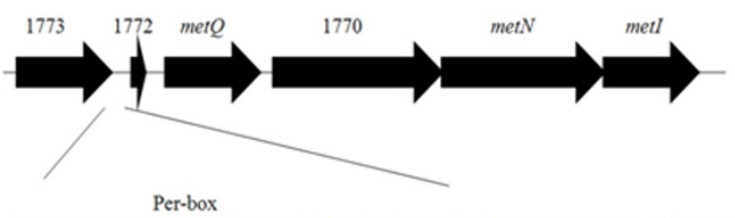

AATTTTTATACAATGATTGTAAGCAACATCGAGACCTATTTCAGTATTTAGTAGA

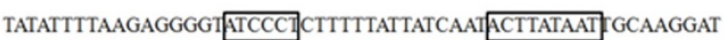
ITGTTATAACGAAAAGTTATAACTTTCTATAAAAAAAGTCAATTAGTCAGAAAG start AAAATTCTGTGTTAAGATAGATACAGTTAATTTAAGGAGATCATTTTATG

Figure 3 Identification of PerR regulon in S. suis. (A) Relative expression levels of genes $\operatorname{dpr}$, metQ, relA, $p m t A$ and sodA in strain $\triangle p e r R$ compared to its parental strain SC-19. Relative abundance of the transcripts was determined by real-time RT-PCR from the total RNAs derived from strains $\Delta$ perR and SC-19 in mid-log phase. gapdh was used as the internal control. (B) Different concentration of PerR proteins binds to dpr and metQIN promoters (500 bp and $300 \mathrm{bp}$ respectively), gidA promoter (300 bp) was used as the negative control. (C) The structure of the $d p r$ and metQIN promoters. -10 and -35 regions of the promoters are shown by the boxes. The start codon is labeled by blod fonts. The predicted PerR-box is underlined.

Dps family proteins have been identified in many bacteria including S. suis. In B. subtilis and S. pyogenes, the Dps homolog MrgA is derepressed when $\mathrm{H}_{2} \mathrm{O}_{2}$ oxidizes PerR $[21,29]$. Usually, If the $\mathrm{Fe}^{2+}$ is present, $\mathrm{H}_{2} \mathrm{O}_{2}$ could be nonenzymatically cleaved into highly toxic hydroxyl radicals by Fenton reaction $\left(\mathrm{H}_{2} \mathrm{O}_{2}+\mathrm{Fe}^{2+} \rightarrow \mathrm{OH}+{ }^{-} \mathrm{OH}+\right.$ $\left.\mathrm{Fe}^{3+}\right)$. However, Dpr can prevent the Fenton-reaction by storing iron and converting $\mathrm{Fe}^{2+}$ to $\mathrm{Fe}^{3+}$-mineral $(\mathrm{FeOOH})$ in a ferroxidase dependent way, resulting in avoiding formation of hydroxyl radicals. In addition, Dpr can bind DNA to protect DNA from oxidative damage in most bacteria but not in S. suis [30-32]. According with previous study, $\mathrm{H}_{2} \mathrm{O}_{2}$ resistance was markedly reduced in $\Delta d p r$ [24]. In our experiment, we found that the double mutant $\Delta p e r R \Delta d p r$ was also highly sensitive to $\mathrm{H}_{2} \mathrm{O}_{2}$ (Figure 2B). Although other PerR targets might be derepressed in $\triangle p e r R, \mathrm{H}_{2} \mathrm{O}_{2}$ resistance ability was not obviously increased. It suggested that, in catalase negative S. suis, Dpr was especially crucial for $\mathrm{H}_{2} \mathrm{O}_{2}$ resistance, and the main reason for increased $\mathrm{H}_{2} \mathrm{O}_{2}$ resistance in $\Delta p e r R$ was derepression of $d p r$.

All amino acid residues of protein are susceptible to oxidative stress. However, methionine sulfoxide can be reduced to methionine by methionine sulfoxide reductase (Msr). During this reaction, Methionine helps the organisms to reduce $\mathrm{H}_{2} \mathrm{O}_{2}$ to $\mathrm{H}_{2} \mathrm{O} \quad$ (Met $+\mathrm{H}_{2} \mathrm{O}_{2} \rightarrow$ Met $(\mathrm{O})+\mathrm{H}_{2} \mathrm{O} ; \quad \operatorname{Met}(\mathrm{O})+\mathrm{Th}(\mathrm{SH})_{2} \rightarrow$ Met $\left.+\mathrm{Th}(\mathrm{S}-\mathrm{S})+\mathrm{H}_{2} \mathrm{O}\right)$ [33]. In most species, such as humans, mice, yeast and bacteria, the cyclic oxidation and reduction of methionine residue plays an important role in defense against oxidative stress [33-36]. In our study, the metNIQ operon was found to be regulated by PerR. However, the metNIQ operon is repressed via the S-box system in B. subtilis and in some other bacteria [37]. In contrast, we did not find the S-box in the promoter of metNIQ operon in S. suis, but it was replaced by a PerR-box (Figure $3 \mathrm{C}$ ). A recent report also found that metNIQ operon was regulated by PerR in $S$. pyogenes via microarray assay [38]. It seems, that 


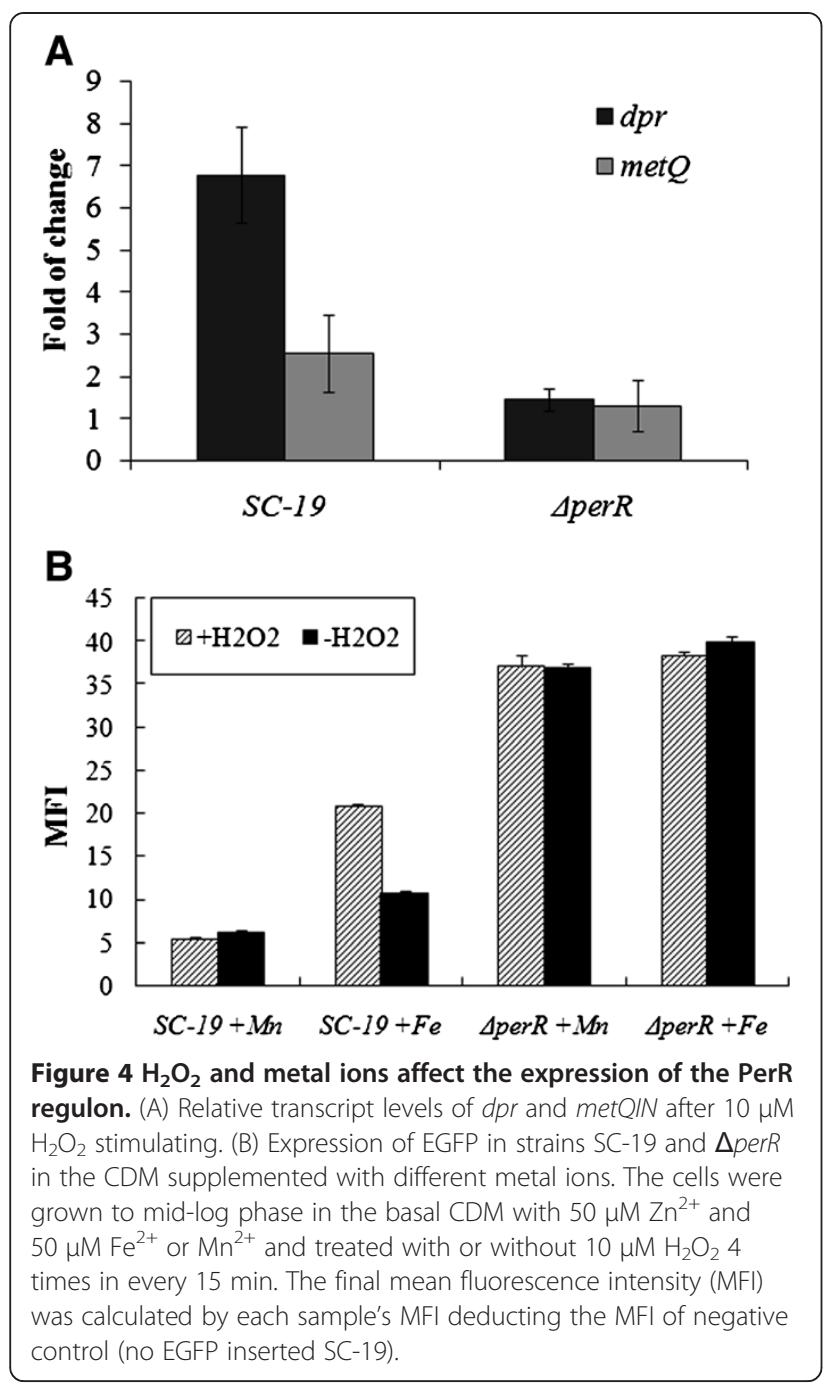

metQIN is negatively regulated by Fur-like protein, is special in the streptococci. We found that metQIN operon could be induced by $\mathrm{H}_{2} \mathrm{O}_{2}$ in SC-19, and in metQIN derepressed $\Delta p e r R$, methionine utilization was increased.
Additionally, methionine concentration was found to be related to $\mathrm{H}_{2} \mathrm{O}_{2}$ resistance. These results suggested that, via controlling the methionine transport, methionine uptake could be regulated by PerR. Thus, oxidative stress response was indirectly affected.

Metal ions level played an important role in oxidative stress response, especially iron level. In our study, using the transcriptional reporter system, we found that PerR represses the regulon by binding to the promoters, and derepression of the regulon could be induced by $\mathrm{H}_{2} \mathrm{O}_{2}$ when abundant $\mathrm{Fe}^{2+}$ was added. In B. subtilis, the regulatory mechanism of PerR has been well studied from the standpoint of its structure, revealing that PerR is a dimeric zinc protein with a regulatory site that coordinates either $\mathrm{Fe}^{2+}$ or $\mathrm{Mn}^{2+}$. PerR can bind $\mathrm{Fe}^{2+}$ or $\mathrm{Mn}^{2+}$ and then repress transcription of its targets, however $\mathrm{Fe}^{2+}$ can catalyze the oxidation of key histidine in PerR, leading to inactivation of PerR [23,39]. PerR in S. suis may have a similar regulatory mechanism to that of $B$. subtilis PerR. According to our results and previous studies, we summarized the putative PerR mediated oxidative stress response pathway in S. suis and showed it in Figure 6.

PerR has been found to be necessary for full virulence of S. pyogenes [20]. Our investigation found that the pathogenicity of perR mutant strain was attenuated. The decreased pathogenicity might be due to the reduced viability of mutant in the host. The fact that the viable number of mutant recovered from mice was much less than that of the wild-type, also supported this explanation. It seems that deletion of perR may lead to inappropriate expression of PerR-regulated genes and affect the normal growth. For example, knockout of perR led to iron starvation and the growth was inhibited in B. subtilis [28]. It was reported that, because Dpr could store iron, the cytosolic iron would be efficiently scavenged when $d p r$ was ectopic overexpressing in S. suis [31]. It suggested that in $\triangle p e r R$, the derepressed $d p r$ would lead to cytosolic iron starvation and affect the growth.
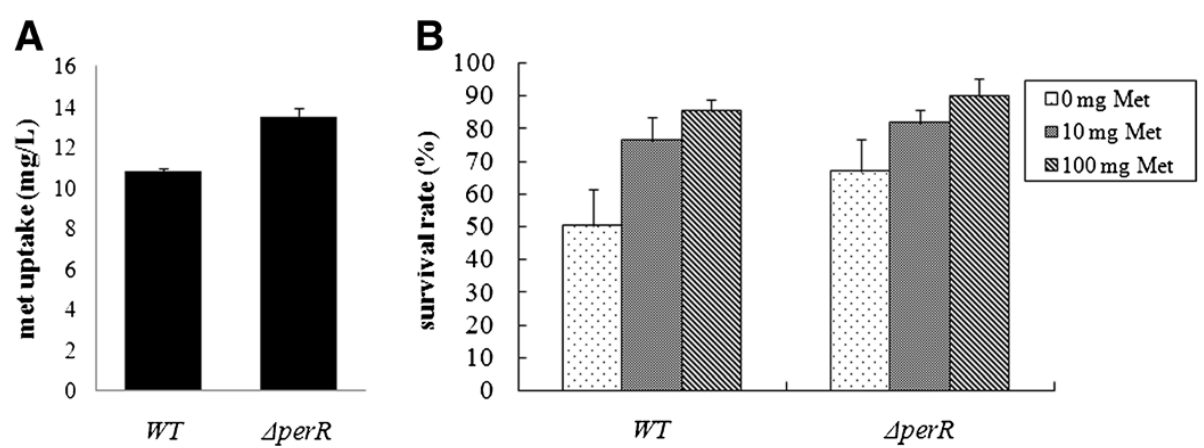

Figure $\mathbf{5}$ Roles of methionine in the $\mathrm{H}_{2} \mathrm{O}_{2}$ resistance. (A) The amount of uptaken methionine in the wild type (WT) and $\Delta$ perR in cells grown to late-log phase. (B) The effects of the methionine to $\mathrm{H}_{2} \mathrm{O}_{2}$ resistance. Survival rates of wild-type (WT) and $\Delta$ perR in $\mathrm{CDM}$ with $5 \mathrm{mM}$ of $\mathrm{H}_{2} \mathrm{O}_{2}$ challenge for $30 \mathrm{~min} .0,10$ and $100 \mathrm{mg} / \mathrm{l}$ of methionine were added in the methionine-free basal CDM respectively. 
Table 2 Survival of SC-19 and $\Delta p e r R$ in different organs in mice

\begin{tabular}{|c|c|c|c|c|}
\hline \multirow[t]{2}{*}{ Source } & \multirow[t]{2}{*}{ Strain } & \multicolumn{3}{|c|}{ Bacteria recovered from blood and tissues $\left(\times 10^{5} \mathrm{CFU}\right)^{a}$} \\
\hline & & $4 \mathrm{dpi}$ & $7 \mathrm{dpi}^{\mathrm{b}}$ & $11 \mathrm{dpi}^{\mathrm{b}}$ \\
\hline \multirow[t]{2}{*}{ Blood } & SC-19 & $4.49 \pm 3.24$ & $2.37 \pm 1.71$ & $0.44 \pm 0.04$ \\
\hline & $\Delta p e r R$ & $4.10 \pm 2.41$ & $0.09 \pm 0.05$ & 0 \\
\hline \multirow[t]{2}{*}{ Lung } & SC-19 & $4.22 \pm 1.45$ & $1.48 \pm 0.11$ & $1.03 \pm 1.59$ \\
\hline & $\Delta p e r R$ & $1.66 \pm 1.11$ & $0.07 \pm 0.04$ & 0 \\
\hline \multirow[t]{2}{*}{ Brain } & SC-19 & $5.07 \pm 3.07$ & $1.42 \pm 0.20$ & $1.62 \pm 1.33$ \\
\hline & $\Delta p e r R$ & $3.84 \pm 2.96$ & $0.13 \pm 0.12$ & $0.01 \pm 0.01$ \\
\hline \multirow[t]{2}{*}{ Spleen } & SC-19 & $0.15 \pm 0.09$ & $0.35 \pm 0.11$ & $0.03 \pm 0.02$ \\
\hline & $\Delta$ perR & $0.22 \pm 0.22$ & $0.04 \pm 0.04$ & 0 \\
\hline
\end{tabular}

${ }^{a}$ Mean \pm standard deviation of 4 independent experiments. Date is expressed as CFU/ml blood, or CFU per tissue.

b $P<0.05$ for comparison of SC-19 versus $\Delta$ perR CFU at 7 and 11 dpi (student's $t$-test).

\section{Conclusions}

These data strongly suggest that the Fur-like protein PerR regulates the oxidative stress response in S. suis. Two members of PerR regulon $d p r$ and metQIN were identified in S. suis, dpr played a crucial role in $\mathrm{H}_{2} \mathrm{O}_{2}$ resistance and metQIN might indirectly affect the $\mathrm{H}_{2} \mathrm{O}_{2}$ resistance by controlling the methionine uptake. Mice infection model showed that the pathogenicity of perR mutant strain was attenuated.

\section{Methods}

Bacterial strains, plasmids, and growth conditions

All the bacterial strains and plasmids used in this study are listed in Table 3. S. suis serotype 2 strain SC-19 was isolated from diseased pigs in Sichuan province, China in 2005 [40]. S. suis was grown in tryptic soy broth (TSB) or on tryptic soy agar (TSA; Difco, Detroit, MI, USA) plates containing $5 \%$ newborn bovine serum (Sijiqing, Hangzhou, China). The CDM [41], modified when necessary, was also used to culture $S$. suis. E. coli strains DH5 $\alpha$ and BL21 (DE3) were cultured in/on Luria-Bertani broth or plates (Oxoid, Basingstoke, UK). When necessary, antibiotics were added to the plates or broth at the following concentrations: $100 \mu \mathrm{g} / \mathrm{ml}$ spectinomycin (Spc), $2.5 \mu \mathrm{g} / \mathrm{ml}$ erythromycin (Erm) or $5 \mu \mathrm{g} / \mathrm{ml}$ chloramphenicol for S. suis; $50 \mu \mathrm{g} / \mathrm{ml} \mathrm{Spc,} 180 \mu \mathrm{g} / \mathrm{ml} \mathrm{Erm,} 12.5 \mu \mathrm{g} / \mathrm{ml}$ Chl or $50 \mu \mathrm{g} / \mathrm{ml}$ kanamycin [22] [22] for E. coli.

\section{Expression and purification of the PerR protein}

The whole coding sequence of perR was amplified from the genomic DNA of S. suis SC-19 using primers $310 \mathrm{~F} /$ 310R (Table 4), which were designed according to the SSU05_0310 sequence of S. suis 05ZYH33 (GenBank accession no. CP000407), and cloned into a prokaryotic expression vector pET-28a (+) (Novagen, Shanghai, China). The resultant plasmid pET28a::perR was confirmed by DNA sequencing and transformed into E. coli BL21 (DE3) for expression of His-tagged recombinant

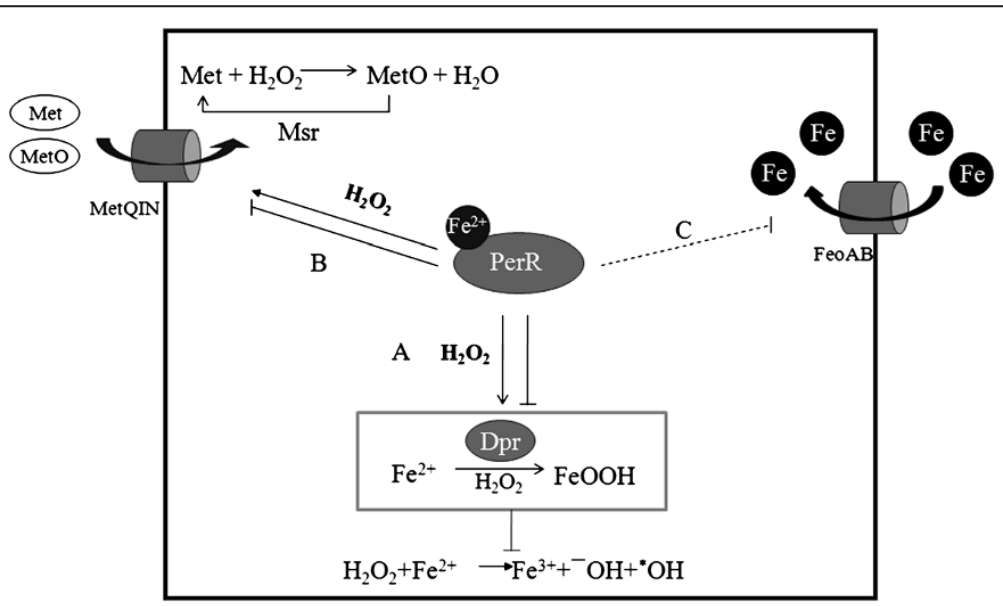

Figure 6 Schematic presentation of the PerR regulatory oxidative stress response in S. suis. (A) $d p r$ is repressed by PerR, and derepression of $d p r$ could be induced by $\mathrm{H}_{2} \mathrm{O}_{2}$. Abundant Dpr stores iron to prevent Fenton reaction. (B) derepression of metQIN is induced by $\mathrm{H}_{2} \mathrm{O}_{2}$, leading to increasing Met (methionine) and MetO (methionine sulfoxide) uptake. During Met cyclic oxidation and reduction, $\mathrm{H}_{2} \mathrm{O}_{2}$ can be reduced to $\mathrm{H}_{2} \mathrm{O}$. (C) FeoAB is negatively regulated by PerR. (The broken lines indicate that the regulatory mechanisms were unclear). 
Table 3 Strains and plasmids used in this study

\begin{tabular}{|c|c|c|}
\hline Strains or plasmids & Characteristics & Reference or source \\
\hline \multicolumn{3}{|l|}{ Strains } \\
\hline SC-19 & Virulent Chinese S. suis serotype 2 isolate, wild-type & This work \\
\hline$\Delta$ perR & Gene perR inactive strain, Erm ${ }^{r}$ & This work \\
\hline$C \Delta$ perR & Complemented $\Delta$ perR strain, $\mathrm{Erm}^{r} \mathrm{Spc}^{r}$ & This work \\
\hline$\Delta d p r$ & Gene $d p r$ inactive strain, $\mathrm{Spc}^{r}$ & This work \\
\hline$\Delta p e r R \Delta d p r$ & Gene perR and dpr inactive strain, $\mathrm{Erm}^{r} \mathrm{Spc}^{r}$ & This work \\
\hline SC-19:EGFP & $P_{d p r}$ EGFP fusion inserted Wild-type, Spc ${ }^{r}$ & This work \\
\hline$\Delta p e r R: E G F P$ & $P_{\mathrm{dpr}}$-EGFP fusion inserted $\Delta p e r R, S p c^{r}$ & This work \\
\hline DH5aand BL21(DE3) & Cloning and expression host & In this lab \\
\hline \multicolumn{3}{|l|}{ Plasmids } \\
\hline pSET4s & Thermosensitive allelic replacement vector & [42] \\
\hline pSET2 & E. coli-S. suis shuttle vector & [44] \\
\hline pET28a & His tag fusion expression vector & Novagen \\
\hline pMIDG310 & A plasmid containing a EGFP gene & \\
\hline pSET4s:: perR & A mosaic plasmid designed to inactivate perR & This work \\
\hline pSET4s::dpr & A mosaic plasmid designed to inactivate $d p r$ & This work \\
\hline pSET2::CperR & Recombinant plasmid used for functional complementation of $\Delta p e r R$ & This work \\
\hline pSET4s:EGFP & Recombinant plasmid used for inserting a $\mathrm{P}_{\mathrm{dpr}}$-EGFP fusion & This work \\
\hline pET28a:: perR & Recombinant expression plasmid to produce His ${ }_{6}$-fused PerR protein & This work \\
\hline pAT18 & A plasmid containing an erm & [45] \\
\hline
\end{tabular}

protein PerR induced by $1 \mathrm{mM}$ isopropyl-beta-D-thiogalactopyranoside at $18^{\circ} \mathrm{C}$ for $4 \mathrm{~h}$. Purification of the recombinant protein was achieved using Ni-NTA agarose (Bio-Rad. USA) under native conditions according to the manufacturer's instructions. Electrophoresis was carried out with $12 \%$ SDS-PAGE.

\section{Construction of strains}

To knockout the gene perR from S. suis SC-19, a thermosensitive homologous suicide vector pSET4s::perR carrying the left arm, right arm and the Erm resistance cassette $\left(\mathrm{erm}^{\mathrm{r}}\right)$ was constructed. The two arms were amplified from the chromosomal DNA of SC-19 by using primers 310 L01/310 L02 and 310R01/310R02 (Table 4), respectively. The $\mathrm{erm}^{\mathrm{r}}$ was amplified from the plasmid pAT18 by using primers ermF/ermR (Table 4). The recombinant plasmid pSET4s::perR was electrotransformed into SC-19, and the strains were selected on Spc and Erm plates as described previously [42]. The suspected mutant strain $\triangle$ perR was verified by PCR, RT-PCR and Southern blot analysis. To construct a functional complementary strain for $\triangle p e r R$, the complete coding sequencing of perR with its upstream promoter was amplified and cloned into the E. coli-S. suis shuttle vector pSET2. The resultant plasmid pSET2::perR was electrotransformed into the mutant strain $\Delta$ perR. The resultant complementary strain was designated as $C \Delta$ perR.

To monitor the regulation to $d p r$ promoter, pSET4s: $\mathrm{P}_{\mathrm{dpr}}$-EGFP, a thermosensitive plasmid containing the transcriptional reporter system was constructed as follow: a 500-bp fragment containing the $d p r$ promoter was amplified from SC-19 genomic DNA using primers PdprF/PdprR and cloned between the EcoRI and BamHI sites of the plasmid pSET4s, resulting in a plasmid pSET4s:P $\mathrm{P}_{\mathrm{dp}}$. The EGFP gene coding sequence was amplified from pMIDG301 (kindly donated by Dr Paul Langford, London, UK) using primers EGFP01/EGFP02 and cloned between the BamHI and Pst I sites of the plasmid pSET4s:P $\mathrm{P}_{\mathrm{dpr}}$. The resultant plasmid pSET4s:P $\mathrm{dpr}$-EGFP was electrotransformed into S. suis SC-19 and $\Delta p e r R$, respectively. The fragment containing the $d p r$ promoter was used as the homologous arm, through a single cross event, the thermosensitive plasmid pSET4s:P $\mathrm{dpr}_{\mathrm{d}}$-EGFP was inserted into the genome at $28^{\circ} \mathrm{C}$ and the rest of plasmids in the strains were lost for continuous passage culture at $37^{\circ} \mathrm{C}$. Spc was used in the whole process. The resultant strains were confirmed by PCR.

\section{GFP assays}

The CDM lacking zinc, iron and manganese was used as the basal medium. Overnight cultured S. suis strains SC19:EGFP and $\Delta p e r R$ :EGFP were washed three times using the basal CDM, and then diluted 1:100 in the basal CDM supplemented with $50 \mu \mathrm{M} \mathrm{Zn}^{2+}$ and $\mathrm{Fe}^{2+}$ (or $\mathrm{Mn}^{2+}$ ) and $50 \mu \mathrm{g} / \mathrm{ml} \mathrm{Spc}$. Cells were cultured at $37^{\circ} \mathrm{C}$ for $3-4 \mathrm{~h}$ to early mid-log phase $\left(\mathrm{OD}_{600}=0.3\right)$. The cells were induced by $10 \mu \mathrm{M} \mathrm{H}_{2} \mathrm{O}_{2}$ four times at every $15 \mathrm{~min}$. One hour later, $1 \mathrm{ml}$ of each sample was obtained and washed with 
Table 4 Primers used in this study

\begin{tabular}{|c|c|c|c|}
\hline Primers & Sequence & Restriction site & target \\
\hline \multicolumn{4}{|c|}{ General PCR amplification } \\
\hline $310 \mathrm{~F}$ & CGTACAGTCGACTTAGTTCTGGCAATCAGGACA & Sall & perR \\
\hline $310 R$ & CGTATCGGATCCATGGAACTCCATTCTCACTTC & $\mathrm{BamHI}$ & \\
\hline 310 L01: & TAGTAAGCTTCACAGTTGGACCTTGGTT & Hind III & Left arm of perR \\
\hline 310 L02 & TCACCTGCAGCGGCATTTGTCCTGATTG & Pstl & \\
\hline 310R01 & TCACCTGCAGTTAGCATTGAAGTGAGAATGG & Pstl & Right arm of perR \\
\hline 310R02 & AGGTGAATTCTTGCTACTGTAATGGTCG & EcoRl & \\
\hline ermF & TCACCTGCAGGAGTGTGTTGATAGTGCA & Pstl & $e r m^{r}$ \\
\hline ermR & AGGTCTGCAGCTTGGAAGCTGTCAGTAG & Pstl & \\
\hline C310F & TCACCTGCAGGATGATGTGGCTGTGTTG & Pstl & perR and its promoter \\
\hline C310R & TAGTGGATCCAAGTCATGTCCGTCGTAG & $\mathrm{BamHI}$ & \\
\hline PdprF & TCAGAATTCTCGGGCTATAGGTAAAAG & EcoRl & Promoter of $d p r$ \\
\hline PdprR & TCAGGATCCATATCACCCTTTCTTITATT & $\mathrm{BamHI}$ & \\
\hline EGFP 01 & TCAGGATCCATGAGTAAAGGAGAAGAAC & $\mathrm{BamHI}$ & EGFP gene \\
\hline EGFP 02 & TCACTGCAGTGCTATTTGTATAGTTCATC & Pstl & \\
\hline 1772P01 & TCCAGGACTGGTGGCGAC & & Promoter of 1772 \\
\hline 1772P02 & AAAATGATCTCCTTAAATTA & & \\
\hline relAP01 & САТАТСТСТАСТСТТССТС & & Promoter of relA \\
\hline relAP02 & AGCTAGTGTGAGTGCTAC & & \\
\hline gidAP01 & CATGTTGTTCTCTCCTTC & & Promoter of gidA \\
\hline gidAP02 & TTGAGGTCAATGAGGTAG & & \\
\hline \multicolumn{4}{|c|}{ Real-time RT-PCR } \\
\hline $0309 \mathrm{~F}$ & GCAACACTTTCTGCCATCA & & pmtA \\
\hline 0309R & GGTCGCACCTACAACTTCA & & \\
\hline $1771 \mathrm{~F}$ & CGCACCAATCCGTCTITA & & metQ \\
\hline $1771 R$ & TTCGTTGTTGGGTCGT & & \\
\hline $2094 \mathrm{~F}$ & TAAGACCGACGAATCCC & & relA \\
\hline $2094 R$ & TCATCCGCGACAGCT & & \\
\hline $1689 \mathrm{~F}$ & TITATCAGTAGCCCATTCA & & $d p r$ \\
\hline $1689 R$ & AAACGCTCACTCATCTCA & & \\
\hline $1539 \mathrm{~F}$ & AGAAGGCAAGTTGGAAG & & $\operatorname{sod} A$ \\
\hline 1539R & GTAGTTTGGACGGACATT & & \\
\hline $0155 \mathrm{~F}$ & AGAAGTAAACGCTGCTAT & & gapdh \\
\hline 0155R & CAAACAATGAACCGAAT & & \\
\hline
\end{tabular}

PBS three times, green fluorescence was observed by fluorescence microscopy, and the mean fluorescence intensity (MFI) was assayed by flow cytometry. To remove the background of green fluorescence, strain SC-19 was used as the negative control.

\section{$\mathrm{H}_{2} \mathrm{O}_{2}$ sensitivity assays}

The disk diffusion assay to test $\mathrm{H}_{2} \mathrm{O}_{2}$ sensitivity was performed as described previously [43]. The strain was cultured under near-anaerobic conditions to mid-log phase and $100-\mu \mathrm{l}$ aliquots were spread on TSA plates. A sterile 5-mm-diameter filter disk containing $4 \mu \mathrm{l} 1 \mathrm{M} \mathrm{H}_{2} \mathrm{O}_{2}$ was placed on the surface of the TSA plate. After incubation at $37^{\circ} \mathrm{C}$ for $12 \mathrm{~h}$, the size of the area cleared of bacteria (inhibition zone) was measured.

For quantitative analysis, resistance of S. suis to $\mathrm{H}_{2} \mathrm{O}_{2}$ killing was tested as described previously [20], with slight modifications. Overnight cultured bacteria were diluted 100-fold into fresh TSB containing 5\% newborn bovine serum in sealed tubes at $37^{\circ} \mathrm{C}$ without shaking (near-anaerobic conditions). When $\mathrm{OD}_{600}$ of the cells reached $\sim 0.5$, some cells were removed and incubation 
was continued at $37^{\circ} \mathrm{C}$ without agitation, and $10 \mathrm{mM}$ $\mathrm{H}_{2} \mathrm{O}_{2}$ was added to the other part of the bacterial culture. Samples were collected at every 15 min for 1 hour after addition of $\mathrm{H}_{2} \mathrm{O}_{2}$. Appropriate bacterial dilutions were plated on TSA plates for viability counts. Survival rate was calculated by dividing the number of CFUs in the $\mathrm{H}_{2} \mathrm{O}_{2}$ challenge part with the number in the part without $\mathrm{H}_{2} \mathrm{O}_{2}$ challenge. For testing the effect of methionine on $\mathrm{H}_{2} \mathrm{O}_{2}$ resistance, overnight cultured bacteria were diluted 100-fold in CDM with different concentrations of methionine and then tested as above.

\section{Amino acid analysis}

Overnight cultured bacteria were washed three times with $\mathrm{CDM}$ and resuspended in the medium containing $100 \mathrm{mg} / \mathrm{l}$ methionine $\left(\mathrm{OD}_{600}=0.1\right)$, and then incubated at $37^{\circ} \mathrm{C}$ for $\sim 4 \mathrm{~h}$. When the growth of cultures reached the late-log phase $\left(\mathrm{OD}_{600}=1.6\right)$, medium samples were withdrawn from the bioreactor directly into a 2-ml tube. Samples were filtered through $0.22-\mu \mathrm{m}$ filters. Amino acid concentrations of the filtered samples were determined using Amino Acid Analyzer L-8900 (Hitachi, Tokyo, Japan). All standards were commercial amino acids (Ajinomoto, Japan).

\section{Electrophoretic mobility shift assay (EMSA)}

Binding of recombinant PerR protein to DNA fragments containing the putative PerR-box was performed. The DNA fragments of the candidate promoters were amplified from S. suis SC-19 genomic DNA and purified by using the PCR Product Purification Kit (Sangon Biotech, Shanghai, China). Binding reactions were carried out in a $20-\mu \mathrm{l}$ volume containing the binding buffer $(20 \mathrm{mM}$ Tris- $\mathrm{HCl}, \mathrm{pH}$ 8.0; $50 \mathrm{mM} \mathrm{KCl} ; 5 \%$ glycerol; $0.5 \mathrm{mM}$ DTT; $25 \mu \mathrm{g} / \mathrm{ml} \mathrm{BSA}, 100 \mathrm{ng}$ poly dIdC), $0.1 \mu \mathrm{g}$ promoter DNA and different amounts of purified recombinant PerR protein $(0,2,4$, and $8 \mu \mathrm{g})$. Binding reaction was incubated at room temperature for $15 \mathrm{~min}$. The loading buffer was then added to the reaction mixtures and the electrophoresis was carried out with $5 \%$ native polyacrylamide DNA retardation gels at $100 \mathrm{~V}$ for $\sim 1 \mathrm{~h}$. Finally, the gels were stained with ethidium bromide. The 300bp promoter of gidA was used as negative control.

\section{Real-time RT-PCR}

Total RNAs of S. suis strains SC-19 and $\Delta p e r R$ were isolated as follows: overnight cultured bacteria in TSB medium with $5 \%$ newborn bovine serum was diluted 1:100 in fresh serum-containing TSB, and then incubated at $37^{\circ} \mathrm{C}$ to the mid-log phase $\left(\mathrm{OD}_{600}=0.5\right)$. Total RNA was isolated and purified using the SV Total RNA Isolation System (Promega) according to the manufacturer's instructions. The contaminating DNA was removed by DNase I treatment. Transcripts of the target genes were assessed by real-time RT-PCR using SYBR Green detection (TAKARA. Dalian. China) in an ABI 7500 system. gapdh gene served as the internal control. The primers using in the real-time RT-PCR are listed in Table 4. Differences in relative transcript abundance level were calculated using the $2^{-\Delta \Delta C T}$ method.

\section{Mouse model of infection}

All animal experiments were carried out according to the Regulation for Biomedical Research Involving Animals in China (1988). To detect the role of PerR in virulence in S. suis, a total of 24 female 6-week-old Balb/C mice were divided into three groups (8 mice per group). Animals in groups 1 and 2 were inoculated by intraperitoneal injection with $1 \mathrm{ml} \sim 6.125 \times 10^{7} \mathrm{CFU}$ of either $S$. suis SC-19 or $\Delta$ perR diluted in TSB. TSB medium was used as a negative control for group 3. Mice were observed for 1 week. To detect the role of FzpR PerR in colonization, two groups of female 6-week-old Balb/C mice were inoculated by intraperitoneal injection with $1 \mathrm{ml}$ of $5 \times 10^{7} \mathrm{CFU}$ of either SC-19 or $\Delta$ perR diluted in physiological saline. Blood, brain, lung and spleen were collected from mice (4 mice in each group) at 4, 7 and 11 days post infection (dpi). The samples were homogenized and subjected for bacterial viability count on TSA plates.

\section{Acknowledgments}

This work was supported by the National Basic Research Program of China (973 Program, 2012CB518802). We thank Dr. Yosuke Murakami for kindly providing the plasmids.

\section{Authors' contributions}

TZ participated in the design of study, performance of the experiments and the writing of manuscript. YD, TL and YW participated in the performance of the experiments. WL participated in the design of the study. RZ and HC participated in the design of study and the writing of manuscript. All authors read and approved the final manuscript.

Received: 03 November 2011 Accepted: 02 May 2012

Published: 30 May 2012

\section{References}

1. Escolar L, Perez-Martin J, de Lorenzo V (1999) Opening the iron box: transcriptional metalloregulation by the Fur protein. J Bacteriol 181 (20):6223-6229

2. Berg JM, Shi Y (1996) The galvanization of biology: a growing appreciation for the roles of zinc. Science 271(5252):1081-1085

3. Gonzalez-Flecha B, Demple B (1995) Metabolic sources of hydrogen peroxide in aerobically growing Escherichia coli. J Biol Chem 270(23):13681-13687

4. Netzer N, Goodenbour JM, David A, Dittmar KA, Jones RB, Schneider JR, Boone D, Eves EM, Rosner MR, Gibbs JS et al (2009) Innate immune and chemically triggered oxidative stress modifies translational fidelity. Nature 462(7272):522-526

5. Uchida Y, Shigematu H, Yamafuji K (1965) The mode of action of hydrogen peroxide on deoxyribonucleic acid. Enzymologia 29(6):369-376

6. Janssen YM, Van Houten B, Borm PJ, Mossman BT (1993) Cell and tissue responses to oxidative damage. Lab Invest 69(3):261-274

7. Faulkner MJ, Helmann JD (2011) Peroxide stress elicits adaptive changes in bacterial metal ion homeostasis. Antioxid Redox Signal 15(1):175-189

8. Hantke K (1981) Regulation of ferric iron transport in Escherichia coli K12: isolation of a constitutive mutant. Mol Gen Genet 182(2):288-292 
9. Hamza I, Chauhan S, Hassett R, O'Brian MR (1998) The bacterial irr protein is required for coordination of heme biosynthesis with iron availability. J Biol Chem 273(34):21669-21674

10. Patzer SI, Hantke K (1998) The ZnuABC high-affinity zinc uptake system and its regulator Zur in Escherichia coli. Mol Microbiol 28(6):1199-1210

11. Posey JE, Hardham JM, Norris SJ, Gherardini FC (1999) Characterization of a manganese-dependent regulatory protein, TroR, from Treponema pallidum. Proc Natl Acad Sci U S A 96(19):10887-10892

12. Ahn BE, Cha J, Lee EJ, Han AR, Thompson CJ, Roe JH (2006) Nur, a nickelresponsive regulator of the Fur family, regulates superoxide dismutases and nickel transport in Streptomyces coelicolor. Mol Microbiol 59(6):1848-1858

13. Bsat N, Herbig A, Casillas-Martinez L, Setlow P, Helmann JD (1998) Bacillus subtilis contains multiple Fur homologues: identification of the iron uptake (Fur) and peroxide regulon (PerR) repressors. Mol Microbiol 29(1):189-198

14. Gaballa A, Helmann JD (1998) Identification of a zinc-specific metalloregulatory protein, Zur, controlling zinc transport operons in Bacillus subtilis. J Bacteriol 180(22):5815-5821

15. Wertheim HF, Nghia HD, Taylor W, Schultsz C (2009) Streptococcus suis: an emerging human pathogen. Clin Infect Dis 48(5):617-625

16. Tang J, Wang C, Feng Y, Yang W, Song H, Chen Z, Yu H, Pan X, Zhou X, Wang $H$ et al (2006) Streptococcal toxic shock syndrome caused by Streptococcus suis serotype 2. PLoS Med 3(5):e151

17. Lun ZR, Wang QP, Chen XG, Li AX, Zhu XQ (2007) Streptococcus suis: an emerging zoonotic pathogen. Lancet Infect Dis 7(3):201-209

18. Feng Y, Li M, Zhang H, Zheng B, Han H, Wang C, Yan J, Tang J, Gao GF (2008) Functional definition and global regulation of Zur, a zinc uptake regulator in a Streptococcus suis serotype 2 strain causing streptococcal toxic shock syndrome. J Bacteriol 190(22):7567-7578

19. Aranda J, Cortes P, Garrido ME, Fittipaldi N, Llagostera M, Gottschalk M, Barbe J (2009) Contribution of the FeoB transporter to Streptococcus suis virulence. Int Microbiol 12(2):137-143

20. Ricci S, Janulczyk R, Bjorck L (2002) The regulator PerR is involved in oxidative stress response and iron homeostasis and is necessary for full virulence of Streptococcus pyogenes. Infect Immun 70(9):4968-4976

21. Brenot A, King KY, Caparon MG (2005) The PerR regulon in peroxide resistance and virulence of Streptococcus pyogenes. Mol Microbiol 55 (1):221-234

22. Gryllos I, Grifantini R, Colaprico A, Cary ME, Hakansson A, Carey DW, SuarezChavez M, Kalish LA, Mitchell PD, White GL et al (2008) PerR confers phagocytic killing resistance and allows pharyngeal colonization by group A Streptococcus. PLoS Pathog 4(9):e1000145

23. Lee JW, Helmann JD (2006) The PerR transcription factor senses $\mathrm{H} 2 \mathrm{O} 2$ by metal-catalysed histidine oxidation. Nature 440(7082):363-367

24. Pulliainen AT, Haataja S, Kahkonen S, Finne J (2003) Molecular basis of H2O2 resistance mediated by Streptococcal Dpr: Demonstration of the functional involvement of the putative ferroxidase center by site-directed mutagenesis in Streptococcus suis. J Biol Chem 278(10):7996-8005

25. Aranda J, Garrido ME, Fittipaldi N, Cortes P, Llagostera M, Gottschalk M, Barbe J (2010) The cation-uptake regulators AdcR and Fur are necessary for full virulence of Streptococcus suis. Vet Microbiol 144(1-2):246-249

26. Hillmann F, Fischer RJ, Saint-Prix F, Girbal L, Bahl H (2008) PerR acts as a switch for oxygen tolerance in the strict anaerobe Clostridium acetobutylicum. Mol Microbiol 68(4):848-860

27. Horsburgh MJ, Clements MO, Crossley H, Ingham E, Foster SJ (2001) PerR controls oxidative stress resistance and iron storage proteins and is required for virulence in Staphylococcus aureus. Infect Immun 69(6):3744-3754

28. Faulkner MJ, Ma Z, Fuangthong M, Helmann JD (2012) Derepression of the Bacillus subtilis PerR peroxide stress response leads to iron deficiency. J Bacteriol 194(5):1226-1235

29. Herbig AF, Helmann JD (2001) Roles of metal ions and hydrogen peroxide in modulating the interaction of the Bacillus subtilis PerR peroxide regulon repressor with operator DNA. Mol Microbiol 41(4):849-859

30. Haikarainen T, Papageorgiou AC (2010) Dps-like proteins: structural and functional insights into a versatile protein family. Cell Mol Life Sci 67(3):341-351

31. Pulliainen AT, Kauko A, Haataja S, Papageorgiou AC, Finne J (2005) Dps/Dpr ferritin-like protein: insights into the mechanism of iron incorporation and evidence for a central role in cellular iron homeostasis in Streptococcus suis. Mol Microbiol 57(4):1086-1100

32. Haikarainen $T$, Thanassoulas A, Stavros P, Nounesis G, Haataja S, Papageorgiou AC (2010) Structural and thermodynamic characterization of metal ion binding in Streptococcus suis Dpr. J Mol Biol 405(2):448-460
33. Sasindran SJ, Saikolappan S, Dhandayuthapani S (2007) Methionine sulfoxide reductases and virulence of bacterial pathogens. Future Microbiol 2(6):619-630

34. Cabreiro F, Picot CR, Friguet B, Petropoulos I (2006) Methionine sulfoxide reductases: relevance to aging and protection against oxidative stress. Ann N Y Acad Sci 1067:37-44

35. Ezraty B, Aussel L, Barras F (2005) Methionine sulfoxide reductases in prokaryotes. Biochim Biophys Acta 1703(2):221-229

36. Moskovitz J (2005) Methionine sulfoxide reductases: ubiquitous enzymes involved in antioxidant defense, protein regulation, and prevention of aging-associated diseases. Biochim Biophys Acta 1703(2):213-219

37. Hullo MF, Auger S, Dassa E, Danchin A, Martin-Verstraete I (2004) The metNPQ operon of Bacillus subtilis encodes an $A B C$ permease transporting methionine sulfoxide, D- and L-methionine. Res Microbiol 155(2):80-86

38. Grifantini R, Toukoki C (2011) Colaprico A. The Peroxide Stimulon and the Role of PerR in Group A Streptococcus. J Bacteriol, Gryllos I

39. Traore DA, El Ghazouani A, Jacquamet L, Borel F, Ferrer JL, Lascoux D, Ravanat JL, Jaquinod M, Blondin G, Caux-Thang C et al (2009) Structural and functional characterization of 2-oxo-histidine in oxidized PerR protein. Nat Chem Biol 5(1):53-59

40. Li W, Liu L, Chen H, Zhou R (2009) Identification of Streptococcus suis genes preferentially expressed under iron starvation by selective capture of transcribed sequences. FEMS Microbiol Lett 292(1):123-133

41. van de Rijn I, Kessler RE (1980) Growth characteristics of group A streptococci in a new chemically defined medium. Infect Immun 27(2):444-448

42. Takamatsu D, Osaki M, Sekizaki T (2001) Thermosensitive suicide vectors for gene replacement in Streptococcus suis. Plasmid 46(2):140-148

43. King KY, Horenstein JA, Caparon MG (2000) Aerotolerance and peroxide resistance in peroxidase and PerR mutants of Streptococcus pyogenes. J Bacteriol 182(19):5290-5299

44. Takamatsu D, Osaki M, Sekizaki T (2001) Construction and characterization of Streptococcus suis-Escherichia coli shuttle cloning vectors. Plasmid 45 (2):101-113

45. Trieu-Cuot P, Carlier C, Poyart-Salmeron C, Courvalin P (1991) Shuttle vectors containing a multiple cloning site and a lacZ alpha gene for conjugal transfer of DNA from Escherichia coli to gram-positive bacteria. Gene 102 (1):99-104

\section{doi:10.1186/1471-2180-12-85}

Cite this article as: Zhang et al:: A Fur-like protein PerR regulates two oxidative stress response related operons $d p r$ and metQIN in Streptococcus suis. BMC Microbiology 2012 12:85.

\section{Submit your next manuscript to BioMed Central and take full advantage of:}

- Convenient online submission

- Thorough peer review

- No space constraints or color figure charges

- Immediate publication on acceptance

- Inclusion in PubMed, CAS, Scopus and Google Scholar

- Research which is freely available for redistribution 